\title{
PATHOGENESIS AND CLINICAL ASPECTS OF CEREBROVASCULAR DISORDERS
}

\author{
G. F. Adams, M.D., F.R.C.P. \\ Wakehurst House, Belfast City Hospital
}

Cerebrovascular disease probably creates more demand for prolonged or permanent hospital care in this country than any other condition; there are many thousands of invalids disabled by it, often at the peak of active working life, and it has become the third most common cause of death in the United Kingdom. Interest in the natural history of cerebrovascular disorders has been revived recently by these trends, and certain medical and surgical innovations in treatment seem to have stimulated, rather than derived from, advances in knowledge (Shaw, 196I). Resigned acceptance of disability from strokes has been replaced by international endeavour to establish uniform pathological and clinical criteria, to promote research and correlate pathology with clinical findings, and to devise treatment based on accurate diagnosis. The extent of this activity is evident in the transactions of three international conferences sponsored by the American Neurological and Heart Association (Wright and Luckey, 1954; Wright and Millikan, 1958; Millikan, Siekert and Whisnant, 1960), and in the Quarterly Index Medicus where, for 1961 alone, there are 425 references to cerebrovascular disease. The results affect the work of anyone concerned with medical or surgical illness in older people.

Medical teaching once concentrated too much on lesions of the intracranial arteries, presenting disorder of the cerebral circulation as strokes caused by hæmorrhage, thrombosis or embolism, or as transitory ischæmic episodes attributed to vasospasm. Good nursing, good fortune and the patient's own initiative contributed more to recovery than medical attention, which was absorbed in the differential diagnosis of syndromes precisely defined in terms of the territories supplied by specific cerebral arteries. There is less confidence now in the criteria offered for differential diagnosis; topographical arterial syndromes are less fashionable; vasospasm is thought to be only one of several factors that provoke cerebral ischæmia; and vascular insufficiency of the cerebral circulation as a whole, including the large vessels in the neck, is recognized as the most common cause of transient or permanent ischæmic cerebral damage.

The cerebral circulation exists to supply the metabolic needs of the brain, above all oxygen, and the blood supply to the brain depends directly on the systemic blood pressure, its 'dynamic source', and inversely on the peripheral resistance in the cerebral vessels. Mutual adjustment is arranged between these, in response to the metabolic needs of the brain, by the effect of changes in oxygen and carbon-dioxide tension on the vasomotor centres. When the blood pressure falls, vasodilation maintains adequate blood flow and oxygenation in the normal vascular tree, and although the exact compensatory mechanism is not? known, it is clearly most efficient, because in young fit people systolic pressure can be reduced as low as $60 \mathrm{~mm}$. $\mathrm{Hg}$. without ill-effects, even when standing erect (Brain, 1957; Saunders, 1954). The essentials needed to maintain oxygen tension at optimum levels are a clear pathway with effective collaterals, an adequate head of systemic blood pressure, and normal blood chemistry.

\section{The Pathway}

The anatomical pathway of the cerebral circulation passes through the two carotid and two vertebral arteries in the neck to the circle of Willis and through its branches to the brain. Sheldon attributes the remarkable mental and physical capacity retained by some people in extreme old age to the integrity of the 'four good pipes' they have in their necks, maintaining a generous supply of blood to the circle of Willis and its intracranial branches.

Normally the cerebral circulation has most efficient collateral safeguards through the extracranial connections of the carotid and vertebral vessels, the developmental extracranial-intracranial persisting arteries, and the intracranial cerebral anastomoses which occur at three levels:

(i) The large base vessels forming the circle of Willis.

(ii) Connections between perforating vessels to basal cell masses.

(iii) Interarterial connections of the anterior, middle and posterior cerebral arteries at the periphery of their cortical fields of supply (Kaplan, 196r). 
These reserves may be reduced by vascular anomalies or by intrinsic disease of the artery walls which narrow or kink them, influenced sometimes by extraneous factors such as cervical spondylosis. The ramifications of the circle of Willis are subject to a variety of congenital abnormalities which may reduce the efficiency of collateral supply, but the most common cause of arterial narrowing and impaired circulation is arterial degeneration, almost a physiological associate of old age. Thickening and reduplication of the internal elastic lamina, and medial sclerosis are found in most senile cerebral arteries; but atheromatous degeneration is the evil most often predisposing to cerebrovascular accidents. It is commonly, but not invariably, present in ageing cerebral arteries as plaques in the larger vessels or as widespread atherosclerosis of smaller branches, and a relationship with hypertension is suspected because they so often co-exist. However, although narrowing of the cerebral arteries has been evoked as both cause and effect of raised blood pressure, the arteriolosclerosis and necrosis found in systemic arteries elsewhere in relation to hypertension does not occur in the brain. Atheroma is almost the sole cause of stenosis or occlusion of main branches of the aortic arch or of the carotid arteries, occurring usually in the internal carotid just above its origin from the common trunk, but where there is atheroma, all four extracranial cerebral arteries are commonly affected in some degree. Blood flow may be grossly reduced through vertebral arteries narrowed by atheroma and subjected to kinking by head movements, in their course through the cervical vertebræ.

Pathological studies have shown that circulation through the cerebral vessels can be very considerably impaired without clinical evidence of neurological disorder, and an artery as large as the internal carotid may be occluded without incident when collateral compensation is adequate. However, when multiple vessels are involved in anomalous or degenerative lesions, the blood flow may be reduced to such precarious levels that even a slight change in the constancy of the supply of blood, or in its composition, may reduce oxygen tension below critical levels in the brain and produce symptoms and signs of cerebral ischæmia. This is the vulnerable situation described by Corday, Rothenberg and Tracy (1953) as a state of cerebral vascular insufficiency.

Although clinical evidence of insufficiency may be missing until elicited by some additional factor leading to ischæmia or infarction, histological evidence suggestive of it is to be found post mortem. A reduction in the number of nerve cells in the cerebral cortex and subcortical masses of grey matter, and of Purkinje cells in the cerebellum, is probably a physiological 'fall out' with age, but cerebral ischæmia intensifies the process with an associated lymphocytic infiltration and glial reaction. Cerebral function, therefore, becomes as it were 'sensitized' to oxygen deprivation, both by the critical level of the existing circulation, and by poverty of reserves in the neuraxis caused by this steady loss of nerve cells (Biggart, 196I; Dickinson and Thompson, 1961; Hutchinson and Yates, 1957; Sheldon, 1960 and 1963).

In this sensitized state the brain is susceptible to the influence of the many variables described by Adams (1958) as 'ischæmia-modifying factors', which act singly or in combination to cause focal or general symptoms of cerebral ischæmia. The operative factor may be the occlusion of quite a small vessel, a change in blood pressure, in the oxygen-carrying capacity of the blood, or in its thrombogenic and thrombolytic propensities. In effect, the factor becomes the last straw on an overburdened cerebral circulation or its tottering collateral reserves, and it gives way at its weakest point (often quite remote from an apparent source of trouble such as carotid stenosis), with the development of transitory or permanent ischæmic brain damage. There are two main groups of these factors-those that influence the systemice blood pressure, and those that stem from changes in blood chemistry.

\section{Changes in Blood Pressure Hypertension}

Hæmorrhage is the cerebrovascular lesion usually thought of in relation to raised blood pressure, but hypertension may also cause focal ischæmic attacks. The mechanism of these, and their repetitive patterns, have been attributed to vasoconstriction induced by sharp transitory episodes of raised blood pressure. Attacks that are accompanied by evidence of focal damage in the encephalogram may be explained by atherosclerotic damage in the collateral vessels of the affected areas of cerebral cortex. Ischæmia or infarction is inevitable in such areas when blood flow is reduced by generalized vasospasm, and hæmorrhage may subsequently occur either from the damaged walls of ischæmic capillaries, or from the rupture of an atheromatous artery, when the vasospasm passes off and blood flow is restored. However, this is hypothesis, and the true cause of intracerebral hæmorrhage is unknown. In addition to raised intra-arterial pressure, vasospasm is readily induced in cerebral arteries by traction, or in association with subarachnoid hæmorrhage. It may be vigorous and sustained after even a small bleed, and the intra-arterial injection of radiopaque 
dye given too: rapidly may reinforce and prolong vasospasm in vessels as large as the internal carotid artery (Knight and Behrman, 1962). These are risks to consider if angiography or operation are contemplated where cerebral vascular insufficiency is suspected.

Where hypertension and atheroma co-exist, hypertension probably assumes the dominant role in producing vascular accidents, and brings an adverse bias to prognosis of survival after strokes (Marshall and Kæser, 196r; Hodge, McQueen and Smirk, 196r).

\section{Hypotension}

Postural changes, sleep and over-sedation; hæmorrhage, cardiac infarction and other causes of shock; heart block and other arrhythmias, carotid sensitivity and hypotensive drugs; these are the common causes of a fall in blood pressure which must be considered possible trigger mechanisms of intermittent ischæmic attacks, or even infarction, when imposed on underlying cerebral vascular insufficiency. Although extensive carotico-vertebral stenosis is known to be compatible with normal activity and no neurological symptoms, and although experimental hypotensive ischæmic attacks have not been successfully reproduced by experiments with drugs or postural changes, where the circulation is impaired by diffuse atherosclerosis, cerebral metabolism must be endangered by hypotensive episodes. Normal compensatory vasodilation in response to a fall in pressure cannot be expected of the rigid, narrowed peripheral vessels, and the risk of thrombosis is increased by a fall in linear-flow rate and prolonged circulation time through them (Dewar, Owen and Jenkins, 1953).

Possible causes of hypotension should always be sought in diagnosis, and, where there are indications of cerebrovascular insufficiency, hypotensive drugs should be used with caution, keeping a close watch for focal or general signs of ischæmia.

\section{Changes in the Composition of the Blood}

Anoxic anoxia, anæmia, polycythæmia, and altered water and electrolyte balance (expecially with potent diuretics), may precipitate ischæmic attacks or infarction in atheromatous patients, but the alterations in the composition of the blood that have attracted special interest recently are those that change the balance between coagulation and fibrinolytic mechanisms in the blood (Sherry, 1961).

Fibrinolysis is an active thrombolytic process that constantly maintains stability between fibrin deposition and fibrin resolution. Fibrin-platelet microthrombi, constantly forming over atheromatous plaques, do not attain obstructive proportions unless local fibrinolytic mechanisms are depressed, and thrombogenesis is encouraged, by factors such as trauma, inflammation or stasis. Microthrombi may then form rapidly and cause partial occlusion. Transient proximal vasoconstriction induced by serotonin, released from platelets, leads to local ischæmia. This is a strong local stimulus to thrombolytic activity and local fibrin dissolution. The development of ischæmic episodes then depends on the interaction of factors favouring either thrombogenesis or thrombolysis. An added refinement of this hypothesis is the suggestion that microemboli detached from plaques in large arteries cause transient ischæmia in peripheral vessels, which then provokes their dissolution (Denny Brown, 1960). Failure to demonstrate thromboemboli post-mortem does not necessarily invalidate these views. Thrombolytic activity is enhanced after death and may dispose of small emboli. Microemboli may account for some intermittent ischæmic attacks, and there are those who believe that they respond to treatment with dicoumarol, but only after a delay of a week or more. The delay is to be expected, because oral anticoagulants exert their earliest effects on Factor VII and other factors concerned with prothrombin formation. Plasma thromboplastin generation and the primary phases of intravascular clotting are not affected until later, when a true intravascular hypocoagulable state, involving Factor IX, develops.

Experimental thrombolysis has reached the stage of clinical trials, but preparation and standardization of plasminogen activatrrs, or of proteolytic enzymes for clot lysis in vivo, still present problems. Laboratory tests are needed to show when patients are at risk of intravascular clotting and to guide a suitable form of treatment free from the present complications of hæmorrhage and pyrexia.

\section{Symptoms and Signs of Intermittent Ischæmia}

Transitory cerebral ischæmia presents a mixed picture of mental, motor and sensory symptoms, of very different frequency, duration and degree of neurological disturbance in different patients. Owing to the close interdependence of all the main cerebral blood vessels upon one another, obstruction to the blood flow in one particular artery does not necessarily elicit symptoms from the area of brain it supplies. The collateral adjustments made necessary by the obstruction may alter the blood flow in atherosclerotic vessels elsewhere. This, and the variety of possible ischæmiamodifying factors to be considered, add to the difficulties of precise diagnosis, and complicate the assessment of medical treatment, or of the value of vascular surgery, to the individual patient. There are, however, certain well-defined characteristics attributed to insufficiency in the carotid and vertebral-basilar arteries:

Carotid insufficiency commonly presents as recurrent transitory attacks of ipsilateral monocular blindness, or of homonymous hemianopia, with paræsthesiæ and paresis of one or other limb on the opposite side.

Vertebral basilar insufficiency is more likely to involve 
the brain stem, the temporal and occipital lobes, or the cerebellum, than the parieto-frontal areas. Vertigo is common, and blurring of vision rather than blindness, or altitudinal rather than homonymous hemianopia, are to be expected. There may be diplopia, nystagmus and disordered conjugate movements, dysphagia, dysarthria, nausea and vomiting. Facial paræsthesiæ, especially perioral numbness and tingling, are very characteristic and are presumably related to ischæmia of the quintothalamic tract. Motor disturbance takes the form of instability and loss of confidence owing to weakness in the legs, most characteristically evident in those patients who are the victims of 'drop attacks'.

The mechanism of 'drop attacks' was described by Kremer (1958). If the connections from cerebellum and other centres concerned with postural control are disturbed at brain-stem level, the postural-tone-control system of the muscles is deprived of the feed-back mechanism that enables the stretch reflex to be modified to meet postural changes. Postural tone fails and the individual 'folds up and falls to the ground suddenly'. Sheldon has emphasized the frequency of drop attacks as a cause of falls in old age. He attributed the high incidence to vertebral-basilar ischæmia combined with the fall-out, mentioned earlier, of nerve cells in cerebellum, brain-stem and other centres concerned with postural control. He also drew attention to the 'positive supporting reaction' with rapid recovery of postural control induced in the victim of a drop attack by pressure on the soles of the feet, by dorsiflexing them, or by standing the patient up. The brain stem ischæmia is probably caused by temporary occlusion of the third part of an atheromatous vertebral artery when it is nipped in spondylotic cervical vertebræ by their rotation or hyperextension with movements of the head in relation to the trunk, or with movements of the trunk in relation to a fixed head (Sheehan, Bauer and Mayer, 1960). This is a practical point to consider in anæsthesia because forced movements of head or trunk independently of one another may have disastrous consequences in anæsthetized elderly patients, especially if muscle relaxants have been used.

Drop attacks are only one of the problems' of postural instability related to vertebral-basilar ischæmia in old age. The prognosis for survival is bad, because of the vital centres located in the brain stem, and because constant 'weakness at the knees' breeds a sense of insecurity and loss of confidence. Even in the absence of frequent falls or of the drop attacks provoked by spondylosis, many of these patients are eventually confined to bed by discouragement or by a fracture.

\section{Diagnosis and Treatment}

It has been said that the volume of information about order and disorder in the cerebral circulation now being compiled raises more problems for research than it has solved. This may be so, but it is also true that a more rational approach can now be made to the diagnosis of cerebrovascular disorders, and the possibilities, as well as the limitations, of treatment are better understood. This applies more to insufficiency states and impending strokes than to the completed strokes caused by massive infarct or hæmorrhage. Hypertension, cerebral irritation, deepening coma, and progression of signs may distinguish hæmorrhage from infarction, and sometimes there is clear-cut evidence of a source of embolism, but clinical criteria for the differential diagnosis of cerebrovascular accident are no more reliable than those described by Aring and Merritt (1935). It is always important to remember that cerebral tumours quite often masquerade as cerebrovascular accidents. In convalescence, especially from thrombotic infarction, the diagnosis should be re-considered to decide whether further investigation is necessary to exclude an underlying vascular insufficiency.

When a patient presents evidence of intermittent or progressing cerebral ischæmia the questions to ask oneself are these:

I. Is a systemic disorder responsible? History and general examination may show hypertension, anæmia, be the primary cause of symptoms.

2. Is there a state of cerebrovascular insufficiency ? The history is most important and leading questions may be necessary to elicit information about symptoms which seem irrelevant to the patient, or too unimportant to mention. Bizarre visual disturbances, drop attacks, or perioral paræsthesiæ are often passed over by forgetful old people more worried by their vertigo, 'weakness', transitory disturbance of consciousness, or a vague sense of impending disaster. There may be evidence of giant cell arteritis in the temporal vessels accompanied by a dejected state of malaise; there may be carotid stenosis with diminished or absent pulsation in one or other carotid artery and perhaps a systolic thrill or bruit over the vessel (and the bruit should be sought over the eye also where it may arise from an ophthalmic collateral): or there may be occlusion of the innominate or subclavian vessels owing to aortic atheroma reducing the radial as well as the carotid pulse, diminishing the blood pressure in the affected arm, and producing a bruit at the root of the neck (Irvine, Luck, Sutton and Walpita, r963). Neurosurgical advice and angiography are necessary to pinpoint operable defects, but the risks and the likely value of angiography must be weighed for each individual. Cerebrovascular lesions can be elusive, difficult to locate and to identify by angiography. Nylin (r96r) and others have devised techniques to study cerebral circulation, using carotid injections of $32 \mathrm{P}$ labelled erythrocytes and other tracers. Parameters for the speed of circulation through the brain are very uniform in health, but distinctive changes are found in dilution curves plotted in cerebrovascular disease and in some mental disorders. This procedure may be approaching the stage where safe, accurate estimation and interpretation of regional blood flow will be possible. It can be used already to screen patients for angiography, 
eliminating those whose cerebral blood flow is so impaired by diffuse arterial narrowing that the diagnostic value of arteriography would be outweighed by the risks, and by the contraindications to subsequent surgery. However, even in circumstances where elaborate arterial reconstruction might not be contemplated, straightforward endarterectomy of an atheromatous plaque may be possible to restore unobstructed flow in a narrowed carotid artery as collateral insurance against insufficiency or occlusion of other main vessels.

3. If there is a state of cerebrovascular insufficiency, what is the trigger mechanism of the ischamic attacks?

(a) Cervical spondylosis. This is always suspect as the source of symptoms relating to vertebral basilar ischæmia, and a history of neck pain radiating to the occiput or across the shoulder, of symptoms evoked by forced head movements, and of root pains or other signs of cervical nerve root involvement add strong presumptive evidence to the changes that may appear in X-rays of the cervical spine. However, degenerative changes are so common in ageing cervical vertebræ that vertebral-basilar ischæmia cannot be confidently attributed to them unless the symptoms are reproduced by hyperextension or rotation of the neck. Tests of forced head movements such as these should only be applied with the caution necessary when investigating the effects of carotid compression, and a safer alternative may be to try the effect of a supporting plastic collar for a time. It is difficult to persuade old people to wear these collars, but, as Denny Brown observed, if symptoms are really attributable to abnormalities in the cervical vertebræ, restriction of neck movement is a more rational procedure than anticoagulant therapy or radical surgery.

(b) Hypotension. The likely causes of a fall in systemic pressure need not be listed here. Despite the lack of experimental evidence, hypotension must be a very real hazard to the patient with defective cerebral circulation and more studies of blood pressure changes in impending or established strokes are needed. The blood pressure is often raised with the onset of a cerebrovascular accident, falling during the later weeks in those who survive. Unstable vasomotor control and relative hypotension may explain the recurrent mental clouding, lassitude, malaise and distressed appearance of some hemiplegic invalids when they first begin to sit out of bed. Patients such as these have been known to feel better, and to improve, with measures taken to prevent pooling of blood in the viscera and legs, and similar treatment might be effective in some instances of intermittent cerebral ischæmia. Over-sedation should be avoided, choosing a minimal effective dose of a hypnotic that does not leave a hangover next day. Lowered blood pressure is not unusual as a side-effect of treatment with chlorpromazine and promazine, especially when they are given by injection, and the blood pressure should be noted at intervals when phenothiazine derivatives are used.

(c) Changes in blood coagulation or fibrinolysis. These must be considered if there is no direct evidence of systemic disease, cervical spondylosis, or hypotension as main contributing factors to intermittent cerebral ischæmia. Unfortunately it is not yet possible to make laboratory estimates of the essential coagulation and thrombolytic mechanisms to indicate when treatment is necessary either to reduce a tendency to thrombosis formation, or to promote thrombolysis. Something better than dicoumarol anticoagulant therapy may in time be evolved to prevent the formation of fibrinplatelet emboli-if indeed they are responsible for the episodic attacks attributed to them. Active thrombolysis of the established thrombus or embolus is still experimental. Meanwhile anticoagulants have nothing to offer in the immediate treatment of cerebral infarction: they do not improve prospects of survival, nor do they reduce the frequency or extent of recurrences (Hill, Marshall and Shaw, 1962). There seems to be a clear indication for their use in cerebral embolism, and perhaps in slowly progressing stroke, in conscious normotensive patients (Carter, 1960). A reduced deathrate in these patients may be brought about by a lowered incidence of pulmonary infarction, and not because of effects on the cerebral circulation, but this does not lessen the probable value of anticoagulants, at least for a time, in both conditions, and especially in cerebral embolism which most often affects people at the peak of active working life and cannot carry a worse prognosis for survival with anticoagulants than it does without them. The other group of patients for whom anticoagulants have been recommended are those with vertebral-basilar transitory ischæmia (Siekert, Millikan and Whisnant, I96I). It is claimed that the attacks can be abolished by anticoagulants, but it might be wise to try the effect of a collar first for reasons given earlier. The difficulties of control and the hazards of treatment with anticoagulants should restrict their use to patients who have the intellect and will to co-operate, and treatment should be limited to a set period of months except in embolism from rheumatic heart disease.

\section{Prophylactic Surgery}

The scope of neurosurgery in the treatment of cerebrovascular disease has recently been reviewed in this journal (Kennedy and Pennybacker, 1962). In older patients hypertension and degenerative arterial disease restrict the possibilities of intracranial operations on aneurysms. It is sometimes possible to aspirate a subcortical hæmatoma or other intracerebral clot, but the value of this, and of hypothermia or prolonged hypotension in the treatment of apoplexy is very limited. The prevention of impending disaster from carotid stenosis by endarterectomy is more promising and the patients most likely to benefit are those with localized stenosis in one artery causing frequent intermittent symptoms. The operation is essentially prophylactic, only a minute fraction of total blocks being removable, and it will almost always stop recurring symptoms (Edwards and Gordon, 1962).

\section{Mental Barriers to Recovery}

Considerable advances have been made in the treatment of residual disability from cerebrovascular accidents in the past 15 years, but these are too familiar to need mention in detail. They have reduced much of the chronic incapacity formerly endured at home or in long-stay hospital wards by the victims of strokes. The hemiplegic invalids now found in these wards may appear to be the irreducible minimum - the hard core left after all that modern physical re-education can do has been done. Their failure to respond to treatment is seldom explained by physical handicaps alone; there is usually an intellectual defect to 
account for it: As this is often accompanied by incontinence, many of these patients find their way into the long-stay wards of general or mental hospitals with a diagnosis of arteriosclerotic cerebral degeneration, because they are considered to be confused, incapable of cooperation or lacking in drive and initiative. These shortcomings are insuperable handicaps to the recovery of some hemiplegic patients, but there are others, wrongly labelled with them, who in fact are disabled by specific disorders of intellect or higher cortical function and not by incipient dementia. They include impaired comprehension, loss of very recent memory, loss of body awareness with neglect or denial of ownership of the affected limbs, disturbances of postural control, or apraxia. These have been described as mental barriers to recovery (Adams and Hurwitz, 1963), and some at least may be overcome by appropriate treatment if they are recognized in time.

Allison (1962) has reviewed the early symptoms of organic mental states in later life, a neglected field of clinical medicine. He describes practical bedside tests and methods of clinical investigation as a basis for the diagnosis, assessment and treatment of these conditions. He quotes the remark 'whatever may be said in favour of it, old age is a losing game', with the comment that the purpose of his book is to focus attention upon ways and means of ensuring that points in the game are not given away unnecessarily. There may be a prodigal waste of these points in some hemiplegic invalids disabled by mental barriers that we cannot yet teach them to circumvent.

I am indebted to Mrs. Vera Stewart for the manuscript and secretarial help.

\section{REFERENCES}

Adams, G. F., and Hurwitz, L. J. (1963): Mental Barriers to Recovery from Strokes (in preparation).

Adams, R. D. (1958): Recent Developments in Cerebrovascular Disease, Brit. med. f., i, 785.

Allison, R. S. (1962): 'The Senile Brain'. London: Edward Arnold.

Aring, C. D., and MerRITt, H. H. (1935): Differential Diagnosis Between Cerebral Hæmorrhage and Cerebral Thrombosis, Arch. intern. Med., 56, 435 .

BigGaRT, J. H. (1961): 'Pathology of the Nervous System'. London: E. \& S. Livingstone.

BRAIN, W. R. (1957): Order and Disorder in the Cerebral Circulation, Lancet, ii, 858 .

CARTER, A. B. (1960): Immediate Treatment of Cerebral Infarction, Ibid., i, 345.

Corday, E., Rothenberg, S. F., and Tracy, J. P. (1953): Cerebral Vascular Insufficiency, A.M.A. Arch. Neurol. Psychiat., 69, $55 \mathrm{I}$.

DenNy Brown, D. (1960): Recurrent Cerebrovascular Episodes, A.M.A. Arch. Neurol., 2, 194.

Dewar, H. A., Owen, S. G., and Jenkins, A. R. (1953): Effect of Hexamethonium on the Cerebral Circulation in Hypertension, Brit. med. $\mathcal{Y}$., ii, 1017.

Dickinson, C. J., and Thomson, A. D. (1961): A post-mortem Study of Main Cerebral Arteries with Special Reference? to the Cause of Strokes, Clin. Sci., 20, 131 .

EDwards, C. H., and Gordon, N. S. (1962): Surgical Treatment of Narrowing of the Internal Carotid Artery, Brit. med. ., i, 1289 .

Hill, A. B., Marshall, J., and Shaw, D. A. (1962): Cerebrovascular Disease: Trial of Long-term Anticoagulant Therapy, Ibid., ii, roo3.

Hodge, J. V., McQUeEN, E. G., and Smirk, M. (196r): Results of Hypotensive Therapy in Arterial Hypertension, Ibid., $\mathbf{i}, \mathrm{r}$.

Hutchinson, E. C., and Yates, P. O. (1957): Carotico-vertebral Stenosis, Lancet, i, 2.

IRVINE, W. T., LuCK, R. J., SutTon, D., and WalPitA, P. R. (1963): Intrathoracic Occlusion of Great Vessels Causing Cerebrovascular Insufficiency, Lancet, $i$, i 177.

Kaplan, H. A. (1961): Collateral Circulation of the Brain, Neurology (Minneap.), 2, 9.

Kennedy, W. F. C., and PenNybacker, J. (1962): Surgical Aspects of Cerebrovascular Disease, Postgrad. med. F., $38,18$.

KNIGHT, G. C., and BeHRMAN, S. (1962): Ischæmic Strokes, Ibid., 38, 396.

KREMER, M. (1958): Sitting, Standing and Walking, Brit. med. $\mathcal{Y}_{\text {., ii, } 63 .}$

MARShall, J., and KAESER, A. C. (1961): Survival after Non-hæmorrhagic Cerebrovascular Accidents, Ibid., ii, 73.

Millikan, C. H., Siekert, R. G., and Whisnant, J. P. (I96r): 'Cerebral Vascular Diseases' (Third Conference). New York: Grune and Stratton.

NyLIN, G. (196I): Incipient Strokes: Application of Blood Flow Measurements in 'Cerebral Vascular Diseases'. Edited by C. H. Millikan, R. G. Siekert and J. P. Whisnant. New York: Grune and Stratton.

SAunders, J. W. (1954): Effect of Controlled Hypotension on Cerebral Function and Circulation, Lancet, i, 1156.

SHAw, D. A. (196r): Diagnosis and Treatment of Cerebrovascular Disease, Postgrad. med. F., 37, 412.

SheEhan, S., BAUER, R. B., and MeYer, J. S. (1960): Vertebral Artery Compression in Cervical Spondylosis, Neurology (Minneap.), 10, 968.

Sheldon, J. H. (1960): On the Natural History of Falls in Old Age, Brit. med. Y., ii, 1685.

(1963): Neurological and Psychiatric Aspects of Old Age, $\mathcal{F}$. Coll. gen. Pract., 4, Suppl. I.

SHERRY, S. (196r): Dynamics of Thrombosis in 'Cerebral Vascular Diseases' (Third Conference). Edited by C. H. Millikan, R. G. Siekert and J. P. Whisnant. New York: Grune and Stratton.

Siekert, R. G., Millikan, C. H., and Whisnant, J. P. (I961): Anticoagulant Therapy in Intermittent Cerebrovascular Insufficiency, $\mathcal{F}$. Amer. med. Ass., 176, 19.

Wright, I. S., and LuCKEY, E. H. (1954): 'Cerebral Vascular Diseases' (First Conference). New York: Grune and Stratton.

—, and Millikan, C. H. (1958): 'Cerebral Vascular Diseases' (Second Conference). New York: Grune and Stratton. 